\title{
APPLICATION OF CENTRAL COMPOSITE DESIGN AND RESPONSE SURFACE METHODOLOGY FOR OPTIMIZATION OF METAL ORGANIC FRAMEWORK: NOVEL CARRIER FOR DRUG DELIVERY
}

\author{
PREETI KUSH ${ }^{1 *}$, JITENDER MADAN ${ }^{1}$, PARVEEN KUMAR ${ }^{2}$ \\ ${ }^{1}$ Department of Pharmaceutics, Chandigarh College of Pharmacy, I. K. Gujral Punjab Technical University, Jalandhar, Punjab, India. \\ ${ }^{2}$ Department of Nanotechnology, Nanotechnology Divisions (H-1), CSIR-Central Scientific Instruments Organisation, Sector 30C, \\ Chandigarh, India. Email: preetikush85@gmail.com
}

Received: 27 March 2019, Revised and Accepted: 19 June 2019

ABSTRACT

Objective: The aim of the present study is to optimize the synthesis method of metal-organic framework (MOF) for high yield and larger surface area with minimum size for efficient drug loading.

Materials and Methods: Materials of Institute Lavoisier (MIL)-101- $\mathrm{NH}_{2}$ was synthesized by microwave-assisted hydrothermal method. Central composite design (CCD) under response surface methodology (RSM) was used for optimization. Process optimization was done by validating the model to obtain maximum surface area, maximum yield, and minimum particle size. Final obtained formulation was characterized by particle size and zeta potential, scanning electron microscopy, powder X-ray diffraction, Fourier-transform infrared spectroscopy, Brunauer-Emmett-Teller, and thermogravimetric analysis. Furthermore, gemcitabine (GEM) was used as a model drug for encapsulation in these MOFs for drug delivery carriers.

Results: The results revealed that MIL-101- $\mathrm{NH}_{2}$ of average size-158 nm with high yield (70\%) and high surface area (2347 $\left.\mathrm{m}^{2} / \mathrm{g}\right)$ could be produced

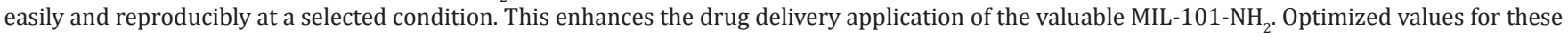
parameters were $170^{\circ} \mathrm{C}, 5.00$, and 1:1:400 for temperature, $\mathrm{pH}$, and reactant ratio, respectively. MIL-101- $\mathrm{NH}_{2}$ appeared as a promising carrier for GEM delivery with higher encapsulation $(77.7 \pm 2 \%)$ and loading $(22.6 \pm 2 \%)$.

Conclusion: The results conclude that processing parameters such as temperature $\mathrm{pH}$ and reactant concentration obtained from CCD-RSM significantly affect the main constraints, i.e., surface area, particle size, and yield. The faster encapsulation of GEM in MOF makes them a promising carrier for drug delivery application.

Keywords: Metal-organic framework, Microwave-assisted hydrothermal method, Optimization, Central composite design, Response surface methodology.

(C) 2019 The Authors. Published by Innovare Academic Sciences Pvt Ltd. This is an open access article under the CC BY license (http://creativecommons. org/licenses/by/4. 0/) DOI: http://dx.doi.org/10.22159/ajpcr.2019.v12i8.34299

\section{INTRODUCTION}

Metal-organic frameworks (MOFs) are a new class of highly tunable hybrid materials coordinated by metal and organic bridging ligand, have emerged as promising drug delivery system. These can be synthesized under mild conditions through coordination-directed self-assembly process [1,2]. Materials of Institute Lavoisier (MIL) family is the first group of MOF discovered by Férey et al. in MIL, France, for the delivery of ibuprofen with chromium-based MIL-101 [3]. MIL family is engineered by trivalent metal centers connected with carboxylic acid. It was found that drugs with polar complexing groups bind eventually to the coordinative unsaturated iron Lewis acid sites (CUS), leading to high encapsulation efficiencies, high payloads, and controlled release [4,5]. Their tunable pore sizes, shapes large surface area to volume ratio (3100-5900 m²/g), intrinsic biodegradability [6], and tailored functionalities have provided a good choice in various applications such as gas storage, catalysis, and chemical sensing, molecular transport, adsorption of organic and inorganic molecules, and luminescence and electrode material [7]. In recent past, different synthesis methods were studied to find out the different structure along with facile preparation. However, optimization of experimental conditions, especially to get nanosized MOF along with higher surface area and higher yield, has been largely unexplored. These properties are beneficial in efficient drug delivery [8].

Among the numerous reported MOFs, MIL-101-NH $\mathrm{NH}_{2}$ (Feaminoterephthalic) is a rigid MOF with a three-dimensional (3D) structure having a pore size of $29 \AA$ [9]. This is widely used for adsorption, catalysis, and drug delivery application. In other reports, MIL101 morphology control was carried out by conventional approach, but poor yield and reproducibility were observed [10]. The conventional and classical approach is based on the selection of one factor at a time (OFAT) which is exhaustive and time consuming. OFAT is unfeasible to give the actual optimal conditions and interactions between the factors [11]. Contrarily to OFAT, statistical experimental design is a method characterized by varying factors simultaneously at different level. Thereby, it is possible to find out the main effects and interactions between the factors using minimum number of experiments without compromising the quality $[12,13]$. Central composite design (CCD) under response surface methodology (RSM) is widely used statistical tool to find out the desired constraints along with the interactions between the factors. Quadratic polynomial equation is used for the selection of the most significant predictive model further evaluated by analysis of variance (ANOVA). $\mathrm{p}$ value and $\mathrm{F}$ values are used to find out the statistical significance of process variables.

In this work, CCD-based methodology has been explored for the $1^{\text {st }}$ time for the optimization of synthesis parameters to obtain nanosized MIL$101-\mathrm{NH}_{2}$. MOF was synthesized by optimizing the reaction conditions such as reactant and solvent concentration, $\mathrm{pH}$, and reaction temperature using microwave radiation with in short time and encapsulation kinetics of gemcitabine (GEM) was investigated. Optimization was carried out with reference to their yield, size, and surface area. Further, morphological and spectroscopic characterization of optimized MIL-101- $\mathrm{NH}_{2}$ was carried out by several instrument techniques such as Fourier-transform infrared 
(FTIR) spectroscopy, powder X-ray diffraction (PXRD), field emission scanning electron microscopy (FESEM), and thermogravimetric analysis (TGA). GEM, as a model drug, was loaded for the synthesis of MOF-based cargo for drug delivery application. The encapsulation efficiency of optimized MIL-101- $\mathrm{NH}_{2}$ was also calculated.

\section{MATERIALS AND METHODS}

\section{Materials}

GEM was purchased from Sigma-Aldrich, India. Iron (III) chloride hexahydrate (Alfa Aesar, 98\%), aminoterephthalic acid and absolute ethanol (Loba Chemie, Mumbai, 99\%) were used for MIL-101- $\mathrm{NH}_{2}$ synthesis and their activation. Deionized water from Millipore Direct $Q$ 3 (Bangalore, India) was used for all aqueous preparations, for example, buffer and solutions.

\section{Synthesis of MIL-101- $\mathrm{NH}_{2}$}

MIL-101- $\mathrm{NH}_{2}$ was synthesized by microwave-assisted hydrothermal method as described elsewhere $[4,14,15]$ without the use of hydrogen fluoride. The method was optimized initially for formulation parameter selection and formulation optimization as shown in Table 1 with a number of important related factors such as the ratio of metal: (200-400) $\mathrm{H}_{2} \mathrm{O}, \mathrm{pH}(2-5)$, and temperature (130-170). Briefly, a mixture of iron chloride ( $9 \mathrm{mmol}$ ) and aminoterephthalic acid ( $5 \mathrm{mmol}$ ) was taken in $200-400 \mathrm{ml}$ of deionized water for $15-60 \mathrm{~min}$ at $130^{\circ} \mathrm{C}$ at $400 \mathrm{~W}$ (Mars-5, CEM, US). As synthesized MOF was collected by centrifugation at $10,000 \mathrm{~g}$ for $10 \mathrm{~min}$. Product was washed with $50 \mathrm{ml}$ of absolute ethanol to remove the residual ligand and collected by centrifugation at $10,000 \mathrm{~g}$ for $10 \mathrm{~min}$. To study the effect of acidity, aqueous solution of $10 \mathrm{~N} \mathrm{NaOH} / 0.1 \mathrm{~N} \mathrm{HCl}$ was added to control the $\mathrm{pH}$. The suspensions were stirred for a maximum of $24 \mathrm{~h}$ at room temperature.

\section{Experimental design}

MIL-101- $\mathrm{NH}_{2}$ was synthesized by microwave-assisted hydrothermal method. It was observed that three independent variables/processing parameters (temperature, $\mathrm{pH}$, and reactant composition) mainly influence the dependent variables (yield, size, and surface area). The effect of these processing variables on dependent variables was studied by rotatable CCD. All the experiments were designed by Design Expert software 10.0.8.0 trial version yielded 20 experiments. The effects of uncontrolled factors were minimized by randomization of experiments. Central points were used to find out the residual error and reproducibility of experiments. The independent variables were coded into low and high values presented by -1 and +1 , respectively. Alpha $(\alpha)$ in coded units was the axial distance from the center point and made the design rotatable. A rotatable design provided equally good predictions at points equally distant from the center, a very desirable property for RSM [16]. Equation 1 represents the mathematical relationship between independent variables, which can be modeled by polynomial model:

$$
Y=\beta_{0}+\sum_{i=1}^{3} \beta i X i+\sum_{i=1}^{3} \sum_{j=1}^{3} \beta i j X i X j+\sum_{i=1}^{3} \beta i i X i^{2}
$$

Where, $\mathrm{Y}$ is the measured response associated with each factor level combinations; $\beta_{0}$ is the intercept; $\beta \mathrm{i}$ (for $\mathrm{i}=1,2$, and 3 ) is the linear

\section{Table 1: Parameters optimization}

\begin{tabular}{|c|c|c|c|c|c|}
\hline $\begin{array}{l}\text { Processing } \\
\text { parameters }\end{array}$ & Units & -1 & +1 & $-\alpha$ & $+\alpha$ \\
\hline $\begin{array}{l}\text { Reactant } \\
\text { composition }\end{array}$ & & 200 & 400 & 131.821 & 468.179 \\
\hline $\mathrm{pH}$ & & 2 & 5 & 0.97731 & 6.02269 \\
\hline Temperature & ${ }^{\circ} \mathrm{C}$ & 130 & 170 & 116.36 & 183.64 \\
\hline
\end{tabular}

effects, the $\beta i$ is the quadratic effects, the $\beta i j$ 's (for $i, j=1,2$, and $3, i<j$ ) is the interaction between the $\mathrm{i}^{\text {th }}$ and $\mathrm{j}^{\text {th }}$ variables. $\mathrm{Xi}$ and $\mathrm{Xj}$ are the coded value for the processing variables.

\section{Model development and statistical analysis}

Statistical significance of developed model along with graphical interpretation was done by Design Expert software (Version 10.0.8.0, Stat-Ease, Inc., Minneapolis, USA). RSM was used to find out the relation between the variables and responses. Numerical optimization method was used for achieving the desired constraints given in Table 2.

\section{Characterization}

Yield, particle size, and zeta potential

The yield of the MIL-100- $\mathrm{NH}_{2}$ was calculated by the ratio of synthesized material to the expected weight based on iron, presented by Equation 2 .

Yield $(\%)=\frac{\text { Actual yield }}{\text { Theoritical yield }} \times 100$

The particle size and zeta potential of MIL-100- $\mathrm{NH}_{2}$ was investigated by zetasizer (Malvern Nano-ZS, Zetasizer Nano series, UK). In brief, a $200 \mu \mathrm{g} / \mathrm{ml}$ dispersion MIL-100- $\mathrm{NH}_{2}$ in distilled water was used to measure the size at $25^{\circ} \mathrm{C}$. A $150 \mathrm{mV}$ electric field was applied to measure the electrophoretic velocity of MIL-100- $\mathrm{NH}_{2}$. All samples were analyzed in triplicate $(\mathrm{n}=3)$.

\section{Scanning electron microscopy (SEM)}

The shape and surface morphology of MOFs were analyzed by FESEM (FESEM; 4300S, Hitachi). For SEM analysis, powder sample of MIL-100$\mathrm{NH}_{2}$ was coated with gold to a thickness of $200-500^{\circ} \mathrm{A}$ under an argon atmosphere using a gold sputter module in a high vacuum evaporator.

PXRD

The architectural arrangement of MIL-100- $\mathrm{NH}_{2}$ was deconvoluted with powder X-ray diffractometer (D5000 Bruker diffractometer). The sample of MIL-100- $\mathrm{NH}_{2}$ was scanned in the $2 \theta$ range of $0-40^{\circ}$. The scanning rate employed was $2^{\circ} / \mathrm{min}$.

\section{FTIR spectroscopy}

FTIR spectroscopy was used to confirm the formation of MIL-100- $\mathrm{NH}_{2}$ by $\mathrm{KBr}$ pellet method. Each pellet was analyzed in the scanning range of $4000-400 \mathrm{~cm}^{-1}$ at resolution of $4 \mathrm{~cm}^{-1}$ using FT-IR spectrophotometer (Perkin Elmer, Massachusetts, USA).

\section{Brunauer-Emmett-Teller (BET) analysis}

MIL-100- $\mathrm{NH}_{2}$ was analyzed for nitrogen adsorption isotherm to calculate the surface area using Belsorp-Max apparatus (MicrotracBel Corporation, Japan) at $773 \mathrm{~K} \mathrm{[2].}$

TGA

TGA was carried out between 20 and $800^{\circ} \mathrm{C}$ under air atmosphere (100 ml/min) using TGA-differential scanning calorimetry (DSC) (SDT-Q-600 TA 2004). The heating rate was $5^{\circ} \mathrm{C} / \mathrm{min}$ for MIL-100- $\mathrm{NH}_{2}$.

\section{GEM encapsulation}

The encapsulation of GEM hydrochloride was carried out by impregnation approach. Impregnation was performed by suspending

Table 2: Relationship between dependent variables and their desired constraints

\begin{tabular}{ll}
\hline Dependent variables & Constraints \\
\hline Yield $(\%)$ & Maximize \\
Size $(\mathrm{nm})$ & Minimize \\
Surface area $\left(\mathrm{m}^{2} / \mathrm{g}\right)$ & Maximize \\
\hline
\end{tabular}


optimized MIL-101- $\mathrm{NH}_{2}$ into aqueous drug solution. In nutshell, $25 \mathrm{mg}$ of lyophilized MIL-101- $\mathrm{NH}_{2}$ was suspended in $5 \mathrm{ml}$ aqueous solution of GEM ( $5 \mathrm{mmol}, 200 \mu \mathrm{g} / \mathrm{ml})$. The suspension was stirred at room temperature for $24 \mathrm{~h}$. Later, suspension was centrifuged (Remi, Mumbai, India) at 10,000 g for $30 \mathrm{~min}$ and supernatant was stored for further analysis at $-20^{\circ} \mathrm{C}$. The pellet of MIL-101- $\mathrm{NH}_{2}$-GEM was further suspended in distilled water and lyophilized (Lab Tech, India) to get the fine powder [18]. The investigation of adsorption behavior of GEM was carried out systemically.

Entrapment efficiency and drug loading capacity (DLC)

The entrapment efficiency (EE) and DLC of optimized sample were calculated by high-performance liquid chromatography (HPLC) method. In brief, $5 \mathrm{mg}$ of MIL-101- $\mathrm{NH}_{2}$-GEM was dispersed by ultrasonication (Soni Weld, India) for $60 \mathrm{~min}$ using $20 \mathrm{ml}$ of acetonitrile:water (50:50) mixture as extracting medium. The samples were centrifuged at $10,000 \mathrm{~g}$ for $20 \mathrm{~min}$ and supernatant was analyzed by HPLC. The encapsulation efficiency (E.E.) and DLC were calculated using Equations 3 and 4:

$\mathrm{EE}(\%)=\frac{\text { Amount of recovered drug }(\mathrm{mg})}{\text { Amount of drug added }(\mathrm{mg})} \times 10$

DLC $=\frac{\text { Amount of recovered drug }(\mathrm{mg})}{\text { Weight of MIL 100-gem }(\mathrm{mg})}$

\section{RESULTS AND DISCUSSION}

CCD-RSM methodology for the optimization of MIL-101- $\mathrm{NH}_{2}$ synthesis

CCD-RSM methodology was used to optimize the synthesis of MIL-101- $\mathrm{NH}_{2}$ using different processing variables, which affect the dependent variables [19]. The design matrix generated by Design Expert consists 20 experiments, including coded and actual values with the obtained results in Table 3.

The effect of the process variables on the responses of the formulation was calculated by multiple regression analysis followed by quadratic polynomial analysis. According to quadratic polynomial analysis, a linear model was suggested to describe the relationship between coded values of the responses and process parameters, represented by Equations 5-7.

Yield $=53.07+1.04 \mathrm{~A}+3.19 \mathrm{~B}+12.35 \mathrm{C}$

Size $=256.49-42.52 A-23.74 B-28.67 C$

Surface area $=1606.25+294.02 \mathrm{~A}+128.25 \mathrm{~B}+134.55 \mathrm{C}$

Where $\mathrm{A}, \mathrm{B}$, and $\mathrm{C}$ are reactant concentration (different water concentration having same metal linker composition), $\mathrm{pH}$, and temperature, respectively. In the above equations, positive sign represents the synergistic effects, whereas negative sign represents antagonistic effect. It was observed from the above equations that there is no interaction between the variables.

Table 3: Experimental conditions and results for the synthesis of MIL-101- $\mathrm{NH}_{2}$

\begin{tabular}{|c|c|c|c|c|c|c|c|}
\hline \multirow[t]{2}{*}{ Type } & \multirow[t]{2}{*}{ Run } & \multicolumn{3}{|l|}{ Experiment condition $^{\mathrm{a}}$} & \multicolumn{3}{|l|}{ Results } \\
\hline & & Reactant composition (A) & pH (B) & Temperature $^{\circ} \mathrm{C}(\mathrm{C})$ & Yield (\%) & $\operatorname{Size}^{\mathrm{b}}(\mathrm{nm})$ & Surface area $\left(\mathrm{m}^{2} / \mathrm{g}\right)$ \\
\hline Center & 1 & Metal:300 $\mathrm{H}_{2} \mathrm{O}$ & 3.5 & 150 & 51.4 & 260 & 1500 \\
\hline Factorial & 2 & Metal:200 $\mathrm{H}_{2} \mathrm{O}$ & 5 & 170 & 75 & 220 & 1500 \\
\hline Center & 3 & Metal:300 H_O & 3.5 & 150 & 51.6 & 258 & 1477 \\
\hline Factorial & 4 & Metal: $400 \mathrm{H}_{2}^{2} \mathrm{O}$ & 2 & 130 & 40.5 & 201 & 1811 \\
\hline Center & 5 & Metal:300 H_O & 3.5 & 150 & 51.2 & 259 & 1476 \\
\hline Axial & 7 & Metal:300 $\mathrm{H}_{2}^{2} \mathrm{O}$ & 3.5 & 116.364 & 31 & 330 & 1227 \\
\hline Factorial & 8 & Metal:400 $\mathrm{H}_{2} \mathrm{O}$ & 5 & 170 & 79 & 158.1 & 2600 \\
\hline Axial & 9 & Metal:300 H & 0.97 & 150 & 50 & 341 & 1219 \\
\hline Axial & 10 & Metal:131 $\mathrm{H}_{2} \mathrm{O}$ & 3.5 & 150 & 51 & 329 & 1240 \\
\hline Axial & 11 & Metal:300 H & 3.5 & 183.636 & 65 & 211 & 1700 \\
\hline Factorial & 12 & Metal:400 H_O & 2 & 170 & 64 & 176.5 & 2400 \\
\hline Factorial & 13 & Metal: $400 \mathrm{H}_{2} \mathrm{O}$ & 5 & 130 & 50 & 185 & 2347 \\
\hline Center & 14 & Metal:300 H_O & 3.5 & 150 & 51.5 & 258.9 & 1478 \\
\hline Axial & 17 & Metal:468 $\mathrm{H}_{2} \mathrm{O}$ & 3.5 & 150 & 52 & 245 & 1512 \\
\hline Factorial & 18 & Metal:200 H_O & 5 & 130 & 45 & 300 & 1500 \\
\hline Center & 19 & Metal:300 $\mathrm{H}_{2} \mathrm{O}$ & 3.5 & 150 & 51.3 & 258.3 & 1476 \\
\hline Center & 20 & Metal:300 H & 3.5 & 150 & 51 & 259 & 1477 \\
\hline
\end{tabular}

As an outcome of CCD-RSM methodology, a total of 20 experiments were performed to optimize the synthesis of MIL-101-NH ${ }_{2}$ using different processing variables such

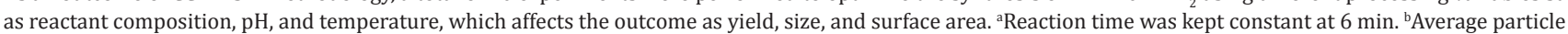
size. MIL: Materials of Institute Lavoisier. CCD: Central composite design, RSM: Response surface methodology

Table 4: ANOVA results for yield of MIL-101- $\mathrm{NH}_{2}$ using linear model

\begin{tabular}{|c|c|c|c|c|c|c|}
\hline Source & Sum of squares & df & Mean square & F-value & p-value & Remarks \\
\hline Model & 2236.73 & 3 & 745.58 & 31.87 & $<0.0001$ & Significant \\
\hline A - Reactant concentration & 14.73 & 1 & 14.73 & 0.6295 & 0.4391 & \\
\hline $\mathrm{B}-\mathrm{pH}$ & 138.56 & 1 & 138.56 & 5.92 & 0.0270 & Significant \\
\hline $\mathrm{C}$ - Temperature & 2083.44 & 1 & 2083.44 & 89.06 & $<0.0001$ & Significant \\
\hline Residual & 374.31 & 16 & 23.39 & & & \\
\hline Lack of fit & 374.08 & 11 & 34.01 & 728.72 & $<0.0001$ & Significant \\
\hline Pure error & 0.2333 & 5 & 0.0467 & & & \\
\hline
\end{tabular}

df: Degree of freedom, p: Probability, $\mathrm{R}^{2}=0.878$, Adjusted $\mathrm{R}^{2}=0.855$, Predicted $\mathrm{R}^{2}=0.775$. ANOVA: Analysis of variance, MIL: Materials of Institute Lavoisier 
Statistical analysis

ANOVA was used to find out the accuracy of the suggested model. Different descriptive statistics such as the probability (p) value, Fisher $(\mathrm{F})$ value, and the degree of freedom (df), and the determination coefficient $\left(\mathrm{R}^{2}\right)$ were calculated by F-test.

In Tables 4-6, the results of the ANOVA were summarized to test the significance of the model for yield, size, and surface area, respectively. F-value, p-value, and sum of squares (SS) are the important parameters for interpretation of ANOVA table. Higher F and SS value implies significance of model and vice versa. p-value parameter is contrary to F-value parameter. $\mathrm{p}<0.05$ indicates the statistical significance of model and used to predict the response function precisely. $\mathrm{p}<0.0001$ revealed that the selected linear model was highly significant and could be used for accurate prediction of responses shown in Tables 4-6. Large value of $R^{2}$ and adjusted $R^{2}$ also represented the goodness of fit (Tables 4-6).

\section{Influence of process variables and their interaction}

Fig. 1 represents that yield was positively influenced by all the three processing parameters without any interaction between the variables. Equation 5 presents temperature and $\mathrm{pH}$ had a significant $(\mathrm{p}<0.05)$ effect on the yield, but insignificant effect was observed in case of reactant concentration evidenced in Fig. $1 \mathrm{~b}$ and c.

The 3D graph in Fig. 2 reveals that size was significantly influenced by all the process parameters. When temperature and $\mathrm{pH}$ were increased, reduction of size is observed in Fig. 2a. Same phenomenon is observed in Fig. $2 b$ and $c$.
Equation 7 revealed that surface area is positively affected by all the processing parameters, i.e., when the concentration was increased, surface area was also increased, but reactant concentration effect was most significant $(\mathrm{p}<0.05)$ also evidenced by Fig. 3 .

Size of MIL-101- $\mathrm{NH}_{2}$ decreased with increasing concentration of solvent. Reduction in size may be due to the dilution of reactant mixture with water. Nucleation, crystal growth, and supersaturation are the factors which affect the particle size [14]. For a smaller particle size, nucleation rate should be faster than the crystal growth rate; therefore, in this case, dilution of reactant mixture with water retards the crystal growth rate but lesser impact on nucleation rate $[20,21]$. There was no effect on crystallinity of the crystals by changing the water concentration. When the particles were reduced by increasing the water concentration, surface area is increased, so it can be postulated that there was an indirect impact of water concentration on surface area. $\mathrm{pH}$ has an important role in the synthesis of materials. When $\mathrm{pH}$ was increased, there was direct impact on yield of product and inverse impact of particle size. For crystallization and growth of hybrid materials, acidity and basicity of reaction medium plays an important role [22]. Acidity and basicity of medium can be changed by adding $\mathrm{NaOH} / \mathrm{HCl}$. The conditions which increase iron trimers concentration produces smaller particle size with fair yield due to increasing nuclei concentration [14]. As previously published in literature, chromium trimers concentration increasing (with decreasing monomer) on increasing $\mathrm{pH}$ from 2 to 4 depends on chromium (III) concentration [23].

In this study, we have increased the pH from 2 to 4.7 by $\mathrm{NaOH}$ solution. This increase in $\mathrm{pH}$ enhances the nucleation rate, which is

Table 5: ANOVA results for size of MIL-101- $\mathrm{NH}_{2}$ using linear model

\begin{tabular}{|c|c|c|c|c|c|c|}
\hline Source & Sum of squares & df & Mean square & F-value & p-value & Remarks \\
\hline Model & $43,613.41$ & 3 & $14,537.80$ & 16.54 & $<0.0001$ & Significant \\
\hline A - Water con. & $24,689.31$ & 1 & $24,689.31$ & 28.10 & $<0.0001$ & Significant \\
\hline $\mathrm{B}-\mathrm{pH}$ & 7699.08 & 1 & 7699.08 & 8.76 & 0.0092 & Significant \\
\hline C - Temperature & $11,225.01$ & 1 & $11,225.01$ & 12.77 & 0.0025 & Significant \\
\hline Residual & $14,060.15$ & 16 & 878.76 & & & \\
\hline Lack of fit & $14,057.76$ & 11 & 1277.98 & 2669.87 & $<0.0001$ & Significant \\
\hline Pure error & 2.39 & 5 & 0.4787 & & & \\
\hline
\end{tabular}

df: Degree of freedom, p: Probability, $\mathrm{R}^{2}=0.756$, Adjusted $\mathrm{R}^{2}=0.710$, Predicted $\mathrm{R}^{2}=0.710$. ANOVA: Analysis of variance, MIL: Materials of Institute Lavoisier

Table 6: ANOVA results for surface area of MIL-101- $\mathrm{NH}_{2}$ using linear model

\begin{tabular}{|c|c|c|c|c|c|c|}
\hline Source & Sum of squares & df & Mean square & F-value & p-value & Remarks \\
\hline Model & $1,653,000$ & 3 & 550,800 & 6.64 & 0.0040 & Significant \\
\hline A - Water con. & $11,810,00$ & 1 & $1,181,000$ & 14.24 & 0.0017 & Significant \\
\hline $\mathrm{B}-\mathrm{pH}$ & 224,600 & 1 & 224,600 & 2.71 & 0.1193 & \\
\hline C - Temperature & 247,200 & 1 & 247,200 & 2.98 & 0.1035 & \\
\hline Residual & 132,700 & 16 & 82937.11 & & & \\
\hline Lack of fit & 132,700 & 11 & 120,600 & 1335.98 & $<0.0001$ & Significant \\
\hline Pure error & 451.33 & 5 & 90.27 & & & \\
\hline
\end{tabular}

df: Degree of freedom, p: Probability, $\mathrm{R}^{2}=0.616$, Adjusted $\mathrm{R}^{2}=0.544$, Predicted $\mathrm{R}^{2}=0.534$. ANOVA: Analysis of variance, MIL: Materials of Institute Lavoisier

Table 7: Comparison of predictive and experimental results optimal values for response function of MIL-101- $\mathrm{NH}_{2}$

\begin{tabular}{|c|c|c|c|c|c|c|c|}
\hline \multirow[t]{2}{*}{ Parameter } & \multirow[t]{2}{*}{ Optimum value } & \multicolumn{3}{|c|}{ Predictive value } & \multicolumn{3}{|c|}{ Experimental value } \\
\hline & & Yield (\%) & Size (nm) & Surface area $\left(\mathrm{m}^{2} / \mathrm{g}\right)$ & Yield (\%) & Size $(\mathrm{nm})$ & Surface area $\left(\mathrm{m}^{2} / \mathrm{g}\right)$ \\
\hline $\begin{array}{l}\text { Reactant } \\
\text { composition }\end{array}$ & $1: 1: 400$ & 69.65 & 161.59 & 2163.07 & $70 \pm 5$ & $158.1 \pm 15$ & $2347 \pm 105$ \\
\hline $\mathrm{pH}$ & 5.00 & & & & & & \\
\hline Temperature & 170 & & & & & & \\
\hline
\end{tabular}

CCD provided data were used for performing experiments and observed that the predictive values are in accordance with experimental values. This approach can help in saving time for optimization of such formulations at production. Experimental values are presented in mean \pm standard deviation ( $\mathrm{n}=3$ ). CCD: Central composite design, MIL: Materials of Institute Lavoisier 
responsible for smaller particle size. Another influence of variation in $\mathrm{pH}$, which affects particle size and yield, is deprotonation extent of organic ligand (BTC) or generation of $\mathrm{OH}$ ligand in aqueous solution. Deprotonation of organic ligand depends on the $\mathrm{pH}$ of reaction media which favors the connectivity of polycarboxylate ligand and metal ions [22]. It has also been reported that higher $\mathrm{pH}(4-5)$ leads to full deprotonation of ligand [24] and promoted the dissolution of organic ligand in aqueous media and easily pure product was obtained. Temperature has a distinct impact on particle size, yield, and surface area as evidenced by Table 3, while there is no change in crystallinity. A possible explanation of reduction in particle size by increasing the temperature could be increased supersaturation of precursor due to higher evaporation of water in an open system, faster nucleation, and crystal growth rate.
Prediction of optimal condition and validation

The precision and accuracy of optimal conditions suggested by Design Expert were validated by performing the same experiments. In this study, we have selected numerical optimization, in which the best target for each factor is given in Table 2. To confirm the model adequacy for predicting the response function, experiments were performed using optimal condition given in Table 7. Results showed good agreement with the predictive and experimental results at the optimum levels, giving a high validity of the model.

\section{Characterization of optimized MIL-101- $\mathrm{NH}_{2}$}

Rigid MOF, MIL-101- $\mathrm{NH}_{2}$ has been synthesized by microwave-assisted method. This simple technology leads to the synthesis of crystalline MOFs.
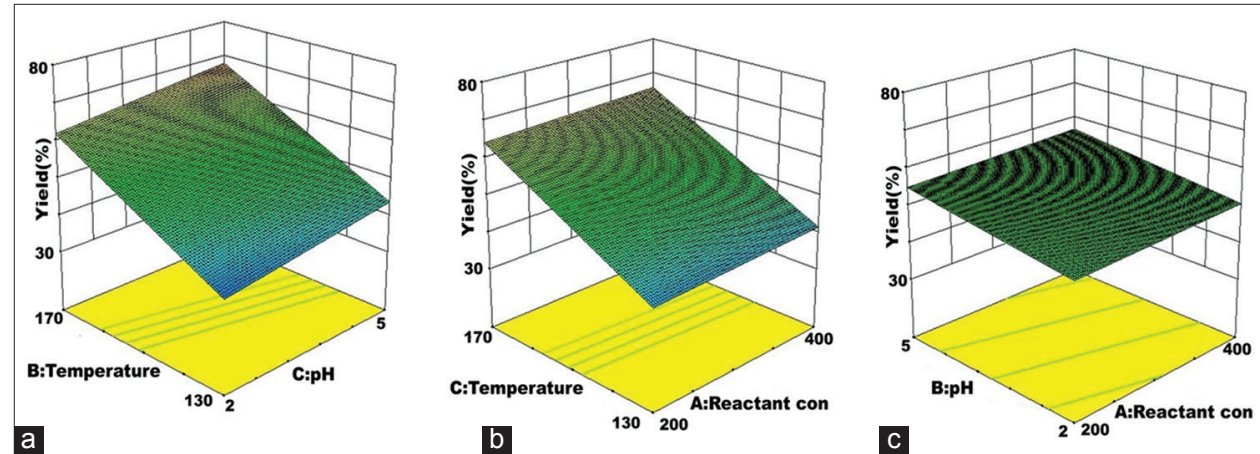

Fig. 1: Effect of process variables on yield of Materials of Institute Lavoisier-101- $\mathrm{NH}_{2}$ computed by central composite design and response surface methodology. (a) Effect of temperature versus $\mathrm{pH}$, reactant concentration was kept constant; (b) effect of temperature versus reactant concentration, $\mathrm{pH}$ value was kept constant; (c) effect of $\mathrm{pH}$ versus reactant concentration, temperature was kept constant

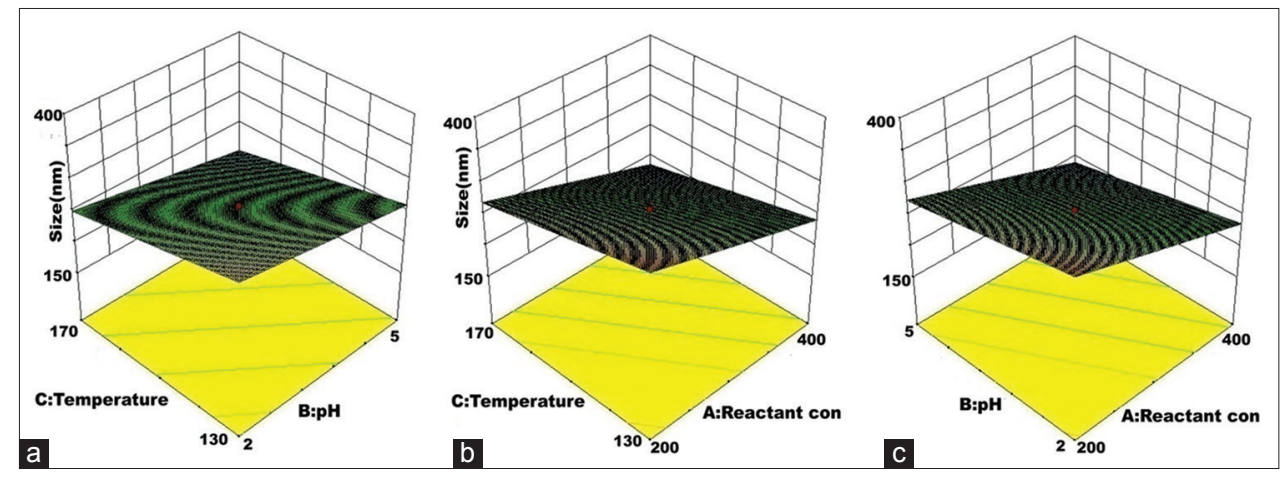

Fig. 2: Effect of process variables on size of Materials of Institute Lavoisier-101- $\mathrm{NH}_{2}$ computed by central composite design and response surface methodology. (a) Effect of temperature versus $\mathrm{pH}$, reactant concentration was kept constant; (b) effect of temperature versus reactant concentration, $\mathrm{pH}$ value was kept constant; (c) effect of $\mathrm{pH}$ versus reactant concentration, temperature was kept constant

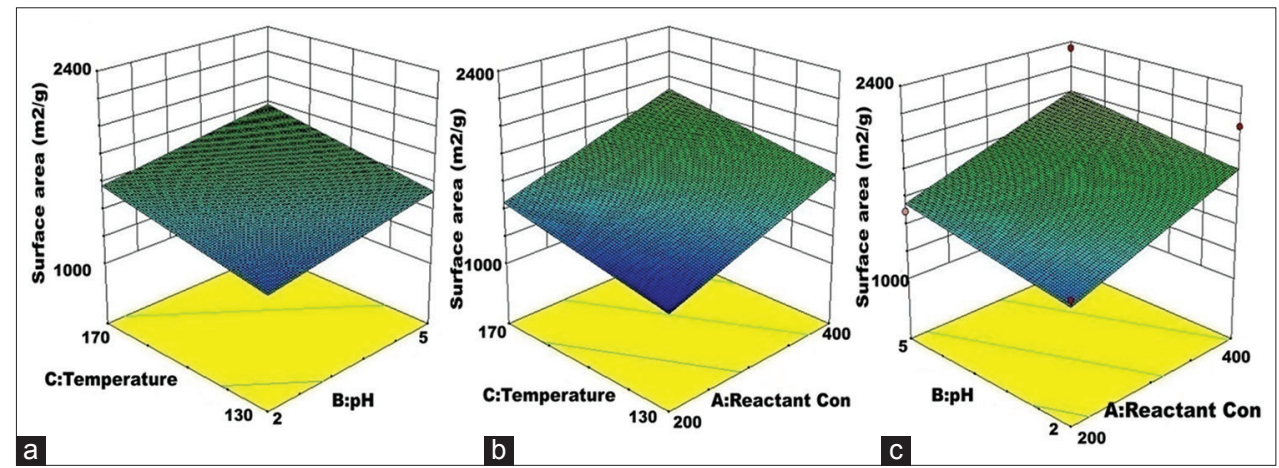

Fig. 3: Effect of process variables on surface area of Materials of Institute Lavoisier-101- $\mathrm{NH}_{2}$ computed by central composite design and response surface methodology. (a) Effect of temperature versus pH, reactant concentration was kept constant; (b) effect of temperature versus reactant concentration, $\mathrm{pH}$ value was kept constant; (c) effect of $\mathrm{pH}$ versus reactant concentration, temperature was kept constant 
The size distributions of MIL-101- $\mathrm{NH}_{2}$ were determined by dynamic light scattering and are presented in Table 7 . The average sizes observed were $158.1 \pm 10$ with polydispersity index values in the range of $0.1-0.3$. PXRD data in Fig. 4 showed crystalline nature of MOF, good agreement

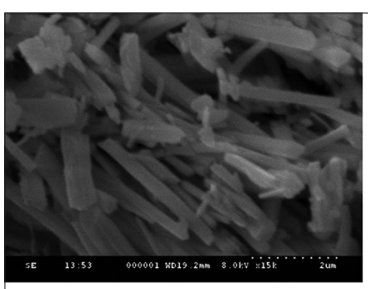

a

Fig. 4: (a) Field emission scanning electron microscopic images of optimized Materials of Institute Lavoisier (MIL)-101- $\mathrm{NH}_{2}$;

(b) X-ray powder diffraction patterns ( $\mathrm{Cu} 1.5406 \AA$ ) of optimized MIL-101-NH

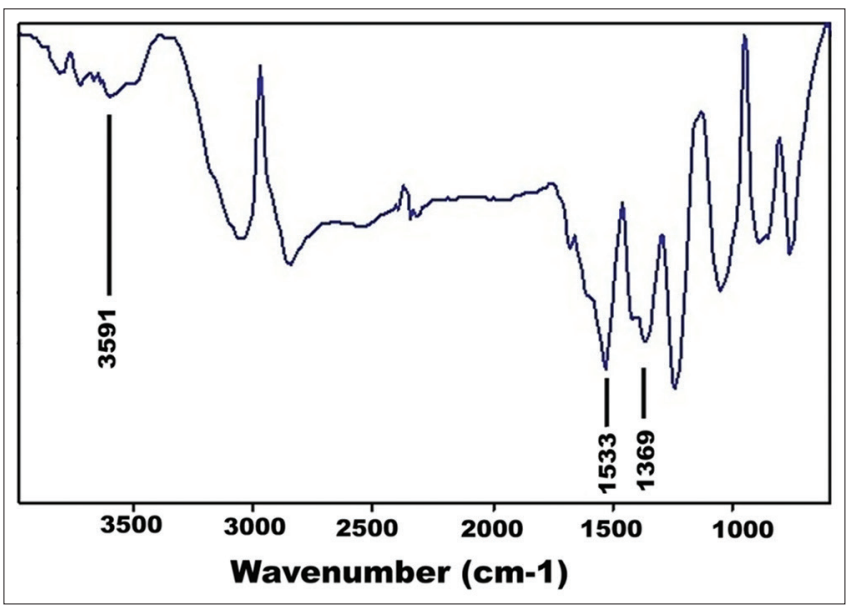

Fig. 5: Infrared spectra of optimized Materials of Institute Lavoisier-101- $\mathrm{NH}_{2}$

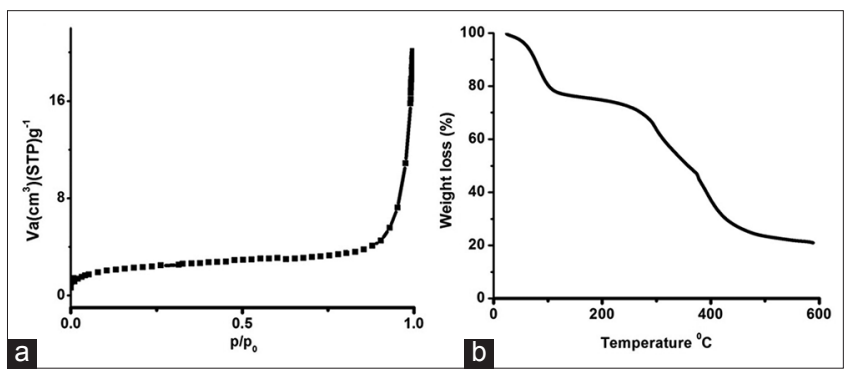

Fig. 6: (a) Nitrogen isotherms of Materials of Institute Lavoisier (MIL)-101- $\mathrm{NH}_{2} ;$ (b) thermogravimetric analysis of MIL-101- $\mathrm{NH}_{2}$

Table 8: Gemcitabine encapsulation within MIL-101- $\mathrm{NH}_{2}$

\begin{tabular}{lll}
\hline $\begin{array}{l}\text { Incubation } \\
\text { time (h) }\end{array}$ & Encapsulation efficiency (\%) & Payload (wt\%) \\
\hline 0.5 & $63.6 \pm 0.4$ & $19 \pm 0.6$ \\
1 & $75.4 \pm 1.1$ & $21.5 \pm 1.2$ \\
2 & $77.7 \pm 2$ & $22.6 \pm 2$ \\
4 & $77.3 \pm 1$ & $22.2 \pm 1.1$ \\
12 & $77.5 \pm 0.8$ & $22.4 \pm 0.8$ \\
24 & $77.3 \pm 1.3$ & $22.47 \pm 1.1$ \\
\hline
\end{tabular}

Different time of gemcitabine incubation with MOF was employed.

Encapsulation efficiency (EE) and drug payload (payload) were recorded. Experimental values are presented in mean \pm standard deviation $(\mathrm{n}=3)$, MIL: Materials of Institute Lavoisier, MOF: Metal-organic framework with literature [25]. Further, infrared spectroscopy in attenuated total reflection mode was performed for the characterization of MIL-101$\mathrm{NH}_{2}$. Fig. 5 shows the characteristic peak of MIL-101- $\mathrm{NH}_{2}$ at 1369, 1533 , and $3591 \mathrm{~cm}^{-1}$ corresponds to C-N stretch C-O stretching and N-H vibration, respectively $[25,26]$.

Surface area was calculated by BET analysis presented in Table 7. This large surface area $\left(2347 \pm 105 \mathrm{~m}^{2} / \mathrm{g}\right)$ gives the suitability of optimized MOF as a drug delivery vehicle. The optimized MOF shows major nitrogen sorption which supported the high porosity of MOF as shown in Fig. 6a. The TGA was carried out between 20 and $800^{\circ} \mathrm{C}$ under air atmosphere $(100 \mathrm{ml} / \mathrm{min})$, using a Perkin-Elmer Diamond TGA/DSC. The heating rate was set at $5^{\circ} \mathrm{C} / \mathrm{min}$ for the MOF; later, an isotherm step at $250^{\circ} \mathrm{C}$ for $6 \mathrm{~h}$ was applied. Two weight losses were observed within the $100-150,200-300$, and $500-600^{\circ} \mathrm{C}$ (Fig. 6b). The first weight loss was due to the departure of water and the second weight loss was due to destruction of the porous solid, i.e., release of linker, i.e., aminoterephthalate.

\section{Kinetics of GEM encapsulation}

To find out encapsulation efficiency and payload, drug molecules were encapsulated by impregnation in MIL-101- $\mathrm{NH}_{2}$, which was performed by incubating the nanoparticles with the drug aqueous solutions in water for $30 \mathrm{~min}$ to $24 \mathrm{~h}$ (Table 8). Soaking of MIL-101- $\mathrm{NH}_{2}$ in GEM aqueous solution acted as an efficient molecular "nanosponges." Drug encapsulation efficiency and maximum payload were measured to be $77.7 \pm 2 \%$ and $22.6 \pm 2 \%$, respectively, after $2 \mathrm{~h}$ which is significantly (unpaired Student's t-test, $\mathrm{P}<0.05$ ) higher than $30 \mathrm{~min}$ incubation (63.6 $\pm 0.4 \%$ and $19 \pm 0.6$ ).

\section{CONCLUSION}

In this investigation, fast microwave-assisted hydrothermal approach was optimized to synthesize MIL-101- $\mathrm{NH}_{2}$ for controlled size along with higher yield and surface area using minimum number of experiments at short time with CCD-RSM. The size, yield, and surface area were mainly influenced by $\mathrm{pH}$, temperature, and reactant concentration without changing the crystallinity and porosity of MOF. Encapsulation kinetics of gemcitabine showed that the MOF behaves like nanosponge, which quickly adsorbs drug in higher amount and makes it a promising drug delivery carrier.

\section{ACKNOWLEDGMENT}

The authors are thankful to I.K. Gujral Punjab Technical University, Punjab, India, for supporting this research work. Parveen Kumar acknowledges the Department of Science and Technology, New Delhi, for INSPIRE Faculty Award.

\section{AUTHORS' CONTRIBUTIONS}

Preeti Kush conceived the idea and all scientific discussions were done in group. Preeti Kush performed all the experiments and maximum characterizations were done by Dr. Parveen Kumar. Dr. Jitender Madan contributed in refining and proof-reading the manuscript.

\section{CONFLICTS OF INTEREST}

The authors have no conflicts of interest to declare.

\section{REFERENCES}

1. Brusa P, Immordino ML, Rocco F, Cattel L. Antitumor activity and pharmacokinetics of liposomes containing lipophilic gemcitabine prodrugs. Anticancer Res 2007;27:195-9.

2. Agostoni V, Chalati T, Horcajada P, Willaime H, Anand R, Semiramoth N, et al. Towards an improved anti-HIV activity of NRTI via metal-organic frameworks nanoparticles. Adv Healthc Mater 2013;2:1630-7.

3. Férey G, Mellot-Draznieks C, Serre C, Millange F, Dutour J, Surblé S, et al. A chromium terephthalate-based solid with unusually large pore volumes and surface area. Science 2005;309:2040-2. 
4. Agostoni V, Horcajada P, Noiray M, Malanga M, Aykaç A, Jicsinszky L, et al. A "green" strategy to construct non-covalent, stable and bioactive coatings on porous MOF nanoparticles. Nature 2015;5:7925-32.

5. di Nunzio MR, Agostoni V, Cohen B, Gref R, Douhal A. A "ship in a bottle" strategy to load a hydrophilic anticancer drug in porous metal organic framework nanoparticles: Efficient encapsulation, matrix stabilization, and photodelivery. J Med Chem 2014;57:411-20.

6. Huxford RC, Rocca JD, Lin W. Metal-organic frameworks as potential drug carriers. Curr Opin Chem Biol 2010;14:262-8.

7. Horcajada P, Serre C, Vallet-Regí M, Sebban M, Taulelle F, Férey G, et al. Metal-organic frameworks as efficient materials for drug delivery. Angew Chem Int Ed Engl 2006;45:5974-8.

8. Saghanejhad TM, Zare-DR. Highly efficient simultaneous ultrasonicassisted adsorption of methylene blue and rhodamine B onto metal organic framework MIL-68(Al): Central composite design optimization. RSC Adv 2016;6:27416-25.

9. Horcajada P, Chalati T, Serre C, Gillet B, Sebrie C, Baati T, et al. Porous metal-organic-framework nanoscale carriers as a potential platform for drug delivery and imaging. Nat Mater 2010;9:172-8.

10. Jhung SH, Lee JH, Yoon JW, Serre C, Férey G, Chang JS. Microwave synthesis of chromium terephthalate MIL-101 and its benzene sorption ability. Adv Mater 2017;19:121-4.

11. Curić A, Reul R, Möschwitzer J, Fricker G. Formulation optimization of itraconazole loaded PEGylated liposomes for parenteral administration by using design of experiments. Int J Pharm 2013;448:189-97.

12. Amir AS, Praveen DC, Sagar SH. A design of experiment approach for optimization and characterization of etodolac ternary system using spray drying. Int J Pharm Pharm Sci 2017;9:223-40.

13. Shekar P, Kumar KS, Jabasingh SA, Radhakrishnan M, Balagurunathan R. Optimization of medium components for antibacterial metabolite production from marine streptomyces sp. Pua2 using response surface methodology. Int J Pharm Pharm Sci 2014; 6:475-80.

14. Khan NA, Kang IJ, Seok HY, Jhung SH. Facile synthesis of nano-sized metal-organic frameworks, chromium-benzenedicarboxylate, MIL101. Chem Eng J 2011;166:1152-7.

15. Agostoni V, Anand R, Monti S, Hall S, Maurin G, Horcajada P, et al. Impact of phosphorylation on the encapsulation of nucleoside analogues within porous iron(iii) metal-organic framework MIL-100(Fe) nanoparticles. J Mater Chem B 2013;1:4231-42.

16. Jyoti K, Pandey RS, Kush P, Kaushik D, Jain UK, Madan J, et al. Inhalable bioresponsive chitosan microspheres of doxorubicin and soluble curcumin augmented drug delivery in lung cancer cells. Int J Biol Macromol 2017;98:50-8.

17. Sumithra S, Shanmugasundaram P, Ravichandiran V. Quality by design-based optimization and validation of new reverse phasehigh-performance liquid chromatography method for simultaneous estimation of levofloxacin hemihydrate and ambroxol hydrochloride in bulk and its pharmaceutical dosage form. Asian J Pharm Clin Res 2016;9:190-6.

18. Chalati T, Horcajada P, Couvreur P, Serre C, Ben Yahia M, Maurin G, et al. Porous metal organic framework nanoparticles to address the challenges related to busulfan encapsulation. Nanomedicine (Lond) 2011;6:1683-95.

19. Kumar S, Varma M, Prakash R. Development and optimization of enzalutamide-loaded solid lipid nanoparticles using box-behnken design. Asian J Pharm Clin Res 2019;12:67-76.

20. Di Renzo F. Zeolites as tailor-made catalysts: Control of the crystal size. Catal Today 1998;41:37-40

21. Jhung SH, Lee JH, Chang JS. Crystal size control of transition metal ion-incorporated aluminophosphate molecular sieves: Effect of ramping rate in the syntheses. Microporous Mesoporous Mater 2008;112:178-86.

22. Seetharaj R, Vandana PV, Arya P, Mathew S. Dependence of solvents, $\mathrm{pH}$, molar ratio and temperature in tuning metal organic framework architecture. Arabian J Chem 2019;12:295-315.

23. Baes CF, Mesmer RE. The Hydrolysis of Cations. New York: John Wiley and Sons; 1976.

24. Yu Q, Zhang X, Bian H, Liang H, Zhao B, Yan S, et al. ph-Dependent $\mathrm{Cu}(\mathrm{II})$ coordination polymers with tetrazole-1-acetic acid: Synthesis, crystal structures, EPR and magnetic properties. Cryst Growth Des 2008;8:1140-6.

25. Wyszogrodzka G, Dorożyński P, Gil B, Roth WJ, Strzempek M, Marszałek B, et al. Iron-based metal-organic frameworks as a theranostic carrier for local tuberculosis therapy. Pharm Res 2018;35:144.

26. Wu B, Lin X, Ge L, Wu L, Xu T. A novel route for preparing highly proton conductive membrane materials with metal-organic frameworks. Chem Commun (Camb) 2013;49:143-5. 